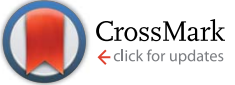

Cite this: Chem. Sci., 2016, 7, 2427

\title{
Selective capture of hexavalent chromium from an anion-exchange column of metal organic resin- alginic acid composite $\uparrow$
}

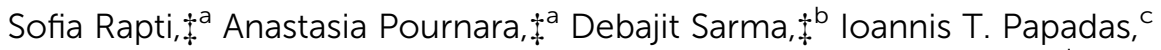 \\ Gerasimos S. Armatas, ${ }^{c}$ Athanassios C. Tsipis, ${ }^{a}$ Theodore Lazarides, ${ }^{d}$ \\ Mercouri G. Kanatzidis ${ }^{b}$ and Manolis J. Manos ${ }^{\star a}$
}

\begin{abstract}
We report an anion exchange composite material based on a protonated amine-functionalized metalorganic framework, denoted Metal Organic Resin-1 (MOR-1), and alginic acid (HA). MOR-1-HA material shows an exceptional capability to rapidly and selectively sorb $\mathrm{Cr}(\mathrm{VI})$ under a variety of conditions and in the presence of several competitive ions. The selectivity of MOR-1-HA for $\mathrm{Cr}(\mathrm{VI})$ is shown to be the result of strong $\mathrm{O}_{3} \mathrm{Cr}^{\mathrm{VI}} \ldots \mathrm{NH}_{2}$ interactions. The composite sorbent can be successfully utilized in an ionexchange column, in contrast to pristine MOR-1 which forms fine suspensions in water passing through the column. Remarkably, an ion exchange column with only $1 \%$ wt MOR-1-HA and $99 \%$ wt sand (an inert and inexpensive material) is capable of reducing moderate and trace $\mathrm{Cr}(\mathrm{vI})$ concentrations to well below the acceptable safety limits for water. The relatively low cost of MOR-1-HA/sand column and its high regeneration capability and reusability make it particularly attractive for application in the remediation of $\mathrm{Cr}(\mathrm{vI})$-bearing industrial waste.
\end{abstract}

Received 1st October 2015

Accepted 18th November 2015

DOI: $10.1039 / \mathrm{c} 5 \mathrm{sc} 03732 \mathrm{~h}$

www.rsc.org/chemicalscience

\section{Introduction}

The contamination of water resources by toxic species represents a major cause of global concern. Among the most commonly found pollutants are various oxo-hydroxy anions. ${ }^{1} \mathrm{~A}$ characteristic example is $\mathrm{Cr}(\mathrm{vI})$-oxo species, found as dichromate $\left(\mathrm{Cr}_{2} \mathrm{O}_{7}{ }^{2-}\right)$, hydrogen chromate $\left(\mathrm{HCrO}_{4}{ }^{-}\right)$or chromate $\left(\mathrm{CrO}_{4}{ }^{2-}\right)$ ions depending on the acidity/basicity of water. $\mathrm{Cr}(\mathrm{vI})$ is a well-known carcinogen, which is released to the environment from leather-tanning, cement, metal plating, dyes industries etc. ${ }^{2}$ Commonly used and inexpensive methods such as precipitation of the ions from solution are not sufficiently effective to lower the concentration of $\mathrm{Cr}(\mathrm{vI})$ below the

\footnotetext{
${ }^{a}$ Department of Chemistry, University of Ioannina, 45110 Ioannina, Greece. E-mail: emanos@cc.uoi.gr

${ }^{b}$ Department of Chemistry, Northwestern University, Evanston, IL 60208, USA

'Department of Materials Science and Technology, University of Crete, 71003 Heraklion, Greece

${ }^{d}$ Department of Chemistry, Aristotle University of Thessaloniki, 54124 Thessaloniki, Greece

$\dagger$ Electronic supplementary information (ESI) available: Synthesis procedures, experimental details of physical measurements, SEM images, thermal analysis, $\mathrm{CO}_{2}$ sorption data and pore size distribution, adsorption isotherms and details for the estimation of selectivity of MOR-1-HA for dichromate, IR spectrum, breakthrough curve in presence of excess of competitive ions and for MOR-1-CA, additional kinetic and characterization data, computational details and optimized geometries for $\mathrm{Ar}-\mathrm{NH}_{3}{ }^{+} \cdots \mathrm{A}$ complexes. See DOI: $10.1039 / \mathrm{c} 5 \mathrm{sc} 03732 \mathrm{~h}$

$\ddagger$ These authors contributed equally.
}

acceptable limits ${ }^{3 a, b}$ and they also generate large amounts of metal-containing sludge. ${ }^{3 c}$ Reduction of $\mathrm{Cr}(\mathrm{VI})$ to $\mathrm{Cr}(\mathrm{III})$ is a promising method, but presents some limitations such as generation of high concentrations of chromium(III) ions in the solution (a secondary treatment of the solution is then needed) or formation of solid waste $\left(\right.$ e.g. $\left.\mathrm{Cr}(\mathrm{OH})_{3}\right) .{ }^{4}$ Absorption and ion exchange are considered as highly effective and relatively inexpensive methods for the treatment of $\mathrm{Cr}(\mathrm{vI})$-containing waste. ${ }^{5}$ Several sorbents have been tested for this purpose. Organic resins, containing functional groups suitable for binding of specific cations or anions, are the most widely-used sorbents in various remediation processes and in the purification of drinking water. ${ }^{5}$ Commercially available resins, with aminefunctional groups, have shown promising $\mathrm{Cr}(\mathrm{vI})$ sorption properties. ${ }^{6}$ Such materials, however, are not only of relatively high cost, but also absorb $\mathrm{Cr}(\mathrm{vI})$ through reduction-precipitation of Cr(III) species. Thus, such resins are actually oxidized-decomposed by $\mathrm{Cr}(\mathrm{vI})$ and they cannot be regenerated and reused. Furthermore, some tests indicated that these $\mathrm{Cr}$ (III)-loaded resins are not safe for disposal as non-hazardous solid waste due to significant Cr leaching. ${ }^{6}$ On the other hand, layered double hydroxides (LDHs), the typical inorganic anionic exchangers, are inexpensive, but show relatively slow sorption kinetics for $\mathrm{Cr}(\mathrm{vI})$ and limited selectivity in the presence of competitive ions. ${ }^{7}$

Metal-organic frameworks (MOFs), ${ }^{8}$ decorated with organic groups having strong binding affinity for toxic ions, may be ideal sorbents for various remediation processes. Such 
functionalized materials, which can be prepared with facile methods and on a large scale, can be called metal-organic resins (MORs), since they combine the organic functionalities of the amorphous organic resins (strong binding groups) ${ }^{5}$ and the ordered porous structure of crystalline MOFs. Thus, MORs with a combination of functional-group based selectivity and a highly porous structure with defined pore size distribution, promise fast sorption kinetics and high efficiencies in practical separation processes. So far, there are limited reports on cationic metal-organic materials showing sorption capability for $\mathrm{Cr}(\mathrm{vI}) .{ }^{9}$ These examples show efficient $\mathrm{Cr}(\mathrm{vI})$ ion exchange capacity. However, all reported materials have been tested with batch methods and no studies on their use in columns have been carried out. Note that industrial wastewater processes require continuous bed flow ion exchange columns. A sorbent material, in order to be appropriate for use in such columns, should display (a) high selectivity and fast sorption kinetics for the targeted ion, (b) particle size suitable to allow continuous flow of wastewater through the column and (c) good mechanical strength to withstand high water pressures. ${ }^{\mathbf{1 0}}$ MORs and other porous materials are usually characterized by very small particle size and insufficient mechanical strength, which hinder their use in columns. Therefore, as-prepared MORs are not suitable for practical environmental remediation applications and thus, novel approaches are required in order to produce an engineered form of the materials to fulfil the requirements of column testing.

Herein we describe the anion exchange composite material based on the $\left[\mathrm{Zr}_{6} \mathrm{O}_{4}(\mathrm{OH})_{4}\left(\mathrm{NH}_{3}{ }^{+}-\mathrm{BDC}\right)_{6}\right] \mathrm{Cl}_{6}$ MOR (MOR-1) and alginic acid (HA) polymer. The MOR is the analogue of the UiO-66 material containing $\mathrm{NH}_{3}{ }^{+}$functional groups (Fig. 1). ${ }^{11}$ Through detailed batch studies, the highly efficient and selective anion exchange properties of the composite for $\mathrm{Cr}(\mathrm{vI})$ are revealed. Importantly, for the first time, we demonstrate the successful use of MORs, in the form of MOR-HA composite, in an ion exchange column. The stationary phase in this column is a mixture of MOR-1-HA and sand (an inert and inexpensive material). Remarkably, a column with MOR-

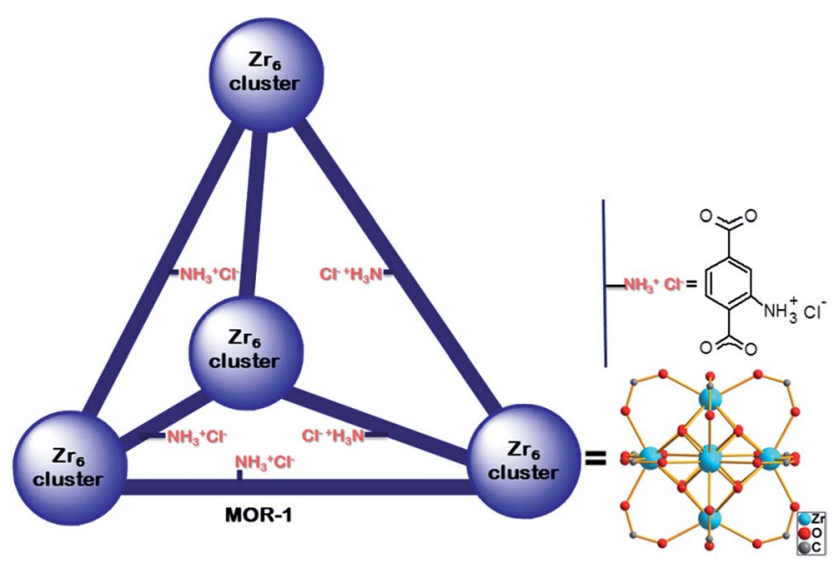

Fig. 1 Representation of the structure of (protonated) MOR-1 material shown as a tetrahedral cage (based on the structure of $\mathrm{UiO}-66$ materia $\left.{ }^{11}\right)$.
1-HA/sand stationary phase containing only 1\% wt MOR-1HA is capable to reduce moderate and trace levels of $\mathrm{Cr}(\mathrm{VI})$ well below the allowed safe levels defined by the USA-EPA (100 $\mathrm{ppb})^{3 a}$ and $\mathrm{EU}(50 \mathrm{ppb}){ }^{3 b}$ despite the presence of a large excess of competitive ions $\left(\mathrm{Cl}^{-}, \mathrm{Br}^{-}, \mathrm{NO}_{3}{ }^{-}, \mathrm{SO}_{4}{ }^{2-}\right.$ etc. $)$. Furthermore, the column can be easily regenerated and reused several times with almost no loss of its capacity. The efficiency and simplicity of this ion exchange column make it attractive for use in the decontamination of wide variety of $\mathrm{Cr}(\mathrm{vI})$-containing wastes.

\section{Results and discussion}

\section{Synthesis of MOR-1-HA composite}

$\mathrm{Zr}^{4+}$ MORs of the UiO-66 family are very promising materials for sorption applications due to their high surface areas, easy incorporation of functional groups and hydrolytic-thermal stability. ${ }^{\mathbf{1 1}}$ However, as mentioned above, as prepared MORs as fine powders are not suitable for practical ion exchange applications. This is particularly true for UiO-66 type MORs usually isolated as nanoparticles (100-200 nm). ${ }^{11 g}$ The latter is a major drawback for the application of such materials as stationary phases in columns. To this end, we applied the alginate encapsulation method to prepare UiO-66 typecomposite solids. ${ }^{12}$ This encapsulation method (method A) involves (a) addition of the sorbent to be encapsulated (i.e. MOR) into an aqueous solution of sodium alginate (SA) so that one or more monolayers of alginate-saturated water cover each particle of the sorbent and (b) addition of $\mathrm{CaCl}_{2}$ to the SA-sorbent suspension so that the monolayer is immediately converted to calcium alginate (CA), forming a waterinsoluble polymer shell around the sorbent particulates (Fig. 2). Then, the MOR-1-CA material was treated with hydrochloric acid to produce $\left[\mathrm{Zr}_{6} \mathrm{O}_{4}(\mathrm{OH})_{4}\left(\mathrm{NH}_{3}{ }^{+}-\mathrm{BDC}\right)_{6}\right] \mathrm{Cl}_{6}{ }^{-}$ HA (MOR-1-HA) (HA = alginic acid) composite with protonated amine groups and extra-framework easily exchangeable $\mathrm{Cl}^{-}$anions (see below), Fig. 2. Note that only $4 \%$ wt of alginate (i.e. alginate : MOR-1 mass ratio used was $\sim 0.04$ ) is sufficient for the composite to be formed and thus, MOR is not encapsulated by thick HA particles that would hinder the diffusion of ions into the MOR pores. Alternatively, MOR-1HA composite may be prepared directly by adding $\mathrm{HCl}$ into a suspension of MOR-1 in SA aqueous solution (method B). The material synthesized with this method shows almost identical structural characteristics and ion-exchange properties with those of composite prepared with method A, as revealed by their very similar PXRD, IR and $\mathrm{Cr}(\mathrm{vI})$ ionexchange isotherm data (see ESI $\dagger$ ). However, for all studies described below, composite samples isolated with method $A$ have been used.

Due to the presence of the HA shell covering the MOR particles, the composite MOR-1-HA material is not easily dispersed in water, in contrast to the pure MOR-1 which forms a fine suspension upon mixing it with water (Fig. 3). This feature of the composite material is proved to be key for its successful utilization in ion-exchange columns (see below). 


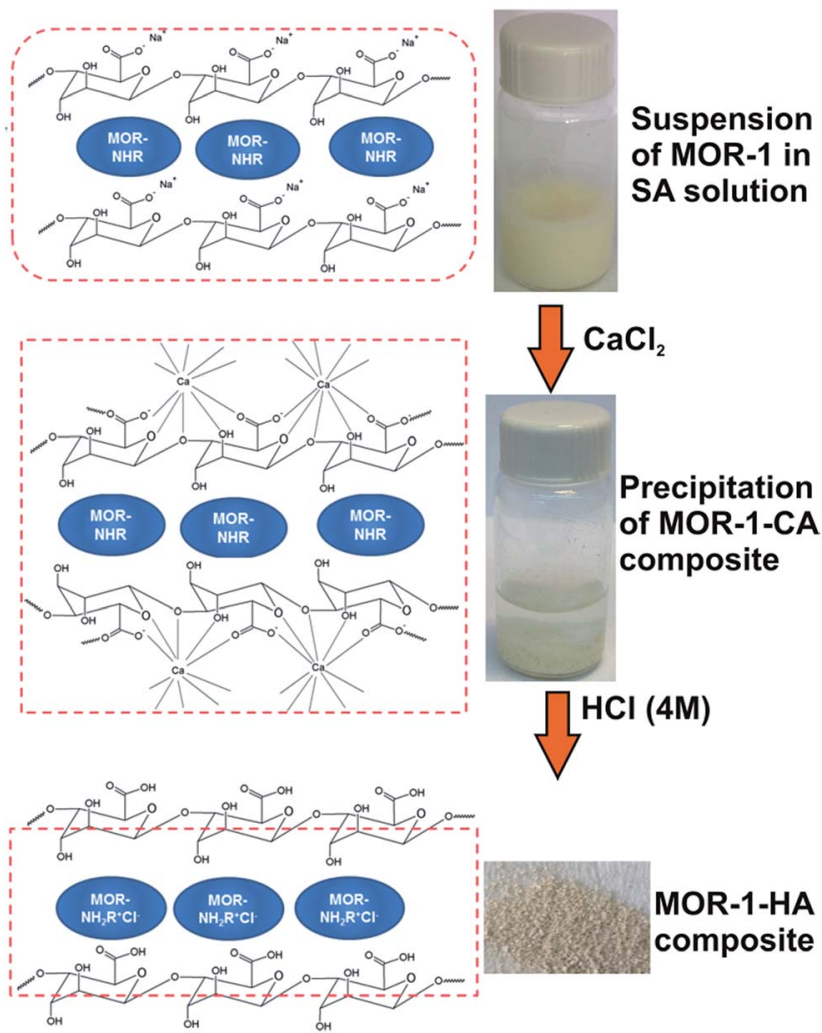

Fig. 2 Schematics for the preparation of the MOR-1-HA composite.

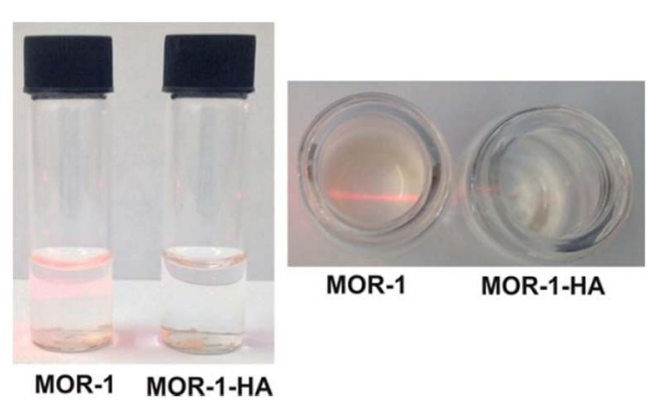

Fig. 3 Upon mixing MOR-1 with water a fine suspension is immediately formed (left vial), whereas MOR-1-HA is clearly separated from water (right vial). This is confirmed by the illumination of the mixtures with a laser pointer. Thus, the laser beam can be easily observed as it travels through the liquid in the left vial (Tyndall effect), whereas it is invisible when it travels through the clear solution in the right vial.

\section{Characterization of MOR-1-HA composite}

Scanning electron microscopy (SEM) images of MOR-1-HA and MOR-1 particles indicate similar morphological characteristics for these materials (Fig. S1, ESI $\dagger$ ). EDS analysis for the MOR-1-HA sample indicates a $\mathrm{Zr}: \mathrm{Cl}$ ratio of $\sim 1$, which is in agreement with the protonation of the six amino-groups of the $\mathrm{Zr}_{6}$ cluster and the presence of six $\mathrm{Cl}^{-}$counter ions. Thermogravimetric analysis (TGA) was used for the determination of the lattice water molecules $\left(21 \mathrm{H}_{2} \mathrm{O}\right.$ molecules, Fig. S2 $\dagger$ ). Powder X-ray diffraction (PXRD) data indicate that the MOR retains its structure in the composite form (Fig. 4A).
The Brunauer-Emmett-Teller (BET) surface area of the MOR1-HA was determined as $1004 \mathrm{~m}^{2} \mathrm{~g}^{-1}$ (Fig. 4B), a value within the range of surface areas found for amino-functionalized UiO-66 materials. ${ }^{11 b, c}$ Analysis of $\mathrm{CO}_{2}$ adsorption data with density function theory (DFT) gives a pore size of about $7 \AA$, (Fig. S3†).

\section{Isolation and characterization of $\mathrm{Cr}(\mathrm{vi})$-loaded material}

Detailed $\mathrm{Cr}(\mathrm{vI})$ sorption studies for MOR-1-HA were performed at low $\mathrm{pH}(\mathrm{pH} \sim 3)$, in order to model the usual acidic conditions of $\mathrm{Cr}(\mathrm{vI})$ industrial waste (for example tannery and metal plating wastewater). ${ }^{13}$ Under such conditions, the predominant $\mathrm{Cr}(\mathrm{vI})$ species is $\mathrm{Cr}_{2} \mathrm{O}_{7}{ }^{2-}$ (with some contribution from $\mathrm{HCrO}_{4}{ }^{-}$ at dilute solutions). ${ }^{2 b}$

By immersing the MOR-1-HA material in $\mathrm{a}_{2} \mathrm{O}_{7}{ }^{2-}$ solution, the removal of $\mathrm{Cr}_{2} \mathrm{O}_{7}{ }^{2-}$ is accomplished at a very fast rate (within a few minutes), an event that can be visually observed by the decolouration of the solution and colour change of the sorbent (Fig. $\mathrm{S} 4 \dagger$ ). This ion exchange process is described by the following equation:

$$
\begin{gathered}
{\left[\mathrm{Zr}_{6} \mathrm{O}_{4}(\mathrm{OH})_{4}\left(\mathrm{NH}_{3}{ }^{+}-\mathrm{BDC}_{6}\right] \mathrm{Cl}_{6}-\mathrm{HA}+3 \mathrm{Cr}_{2} \mathrm{O}_{7}{ }^{2-} \rightarrow\right.} \\
{\left[\mathrm{Zr}_{6} \mathrm{O}_{4}(\mathrm{OH})_{4}\left(\mathrm{NH}_{3}{ }^{+}-\mathrm{BDC}\right)_{6}\right]\left(\mathrm{Cr}_{2} \mathrm{O}_{7}\right)_{3}-\mathrm{HA}+6 \mathrm{Cl}^{-}}
\end{gathered}
$$

EDS data revealed no $\mathrm{Cl}^{-}$anions in the $\mathrm{Cr}(\mathrm{vI})$-loaded material MOR-1-HA@Cr(VI). ICP-MS, EDS and UV-Vis data (see below) indicate a $\mathrm{Zr}$ : $\mathrm{Cr}$ ratio of $0.9-1.2$, closed to the expected one (theoretical $\mathrm{Zr}: \mathrm{Cr}=1$, considering the insertion of $3 \mathrm{Cr}_{2} \mathrm{O}_{7}{ }^{2-}$
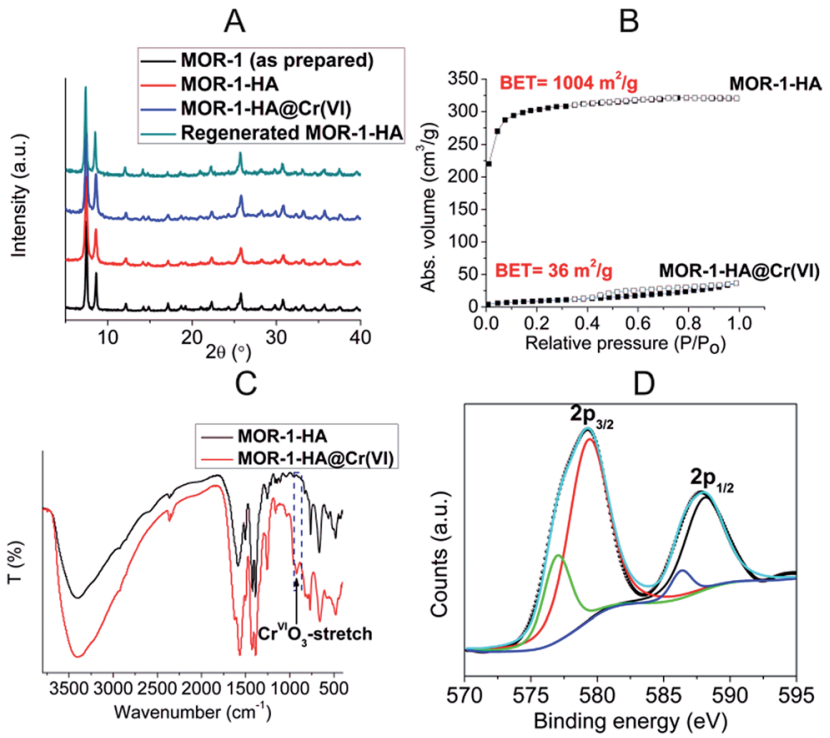

Fig. 4 (A) PXRD patterns of MOR-1 (as prepared), MOR-1-HA, MOR1-HA@Cr(VI) and regenerated MOR-1-HA. (B) Nitrogen adsorptiondesorption isotherms at $77 \mathrm{~K}$ for MOR-1-HA and MOR-1-HA@Cr(VI). (C) IR spectra of MOR-1-HA and MOR-1-HA@Cr(VI). (D) High-resolution $\mathrm{Cr} 2 \mathrm{p}_{1 / 2}$ and $\mathrm{Cr} 2 \mathrm{p}_{3 / 2}$ core-level photoelectron spectra of MOR1-HA with their deconvolution into two components. The minor signals with binding energy at 586.3 and $577.0 \mathrm{eV}$ are attributed to $\mathrm{Cr}(\mathrm{III})$ traces resulted from the known reduction effects under $\mathrm{X}$-ray irradiation. ${ }^{14}$ 
per $\mathrm{Zr}_{6}$ cluster). PXRD data revealed that the MOR structure is retained after the incorporation of the dichromate anions (Fig. 3A).

There is a drastic decrease, however, in the BET surface area for MOR-1-HA@Cr(VI) indicating the pores of the structure are filled by $\mathrm{Cr}(\mathrm{vI})$ species. Specifically, after the insertion of $\mathrm{Cr}_{2} \mathrm{O}_{7}{ }^{2-}$ anions, the surface area for MOR-1-HA drops from $\sim 1000$ to $36 \mathrm{~m}^{2} \mathrm{~g}^{-1}$ (Fig. 4B). Further evidence for the presence of $\mathrm{Cr}$ (VI) species in MOR-1-HA@Cr(VI) was provided by infrared (IR) and X-ray photoelectron spectroscopy (XPS). The IR spectrum (Fig. 4C and $\mathrm{S} 5 \dagger$ ) of the exchanged sample showed the existence of an absorption peak at $\sim 924 \mathrm{~cm}^{-1}$ (not present in the spectra of pristine MOR-1-HA material) assigned to the antisymmetric $\mathrm{Cr}^{\mathrm{VI}} \mathrm{O}_{3}$-stretch (for more detailed interpretation of IR data see also below). XPS data revealed the presence of $\operatorname{Cr} 2 \mathrm{p}_{1 / 2}$ and $\operatorname{Cr} 2 \mathrm{p}_{3 / 2}$ core-level signals, with their main components corresponding to binding energies of 588.1 and $579.3 \mathrm{eV}$ (Fig. 4D). These binding energies are consistent with $\operatorname{Cr}(\mathrm{vI}) .^{14}$

\section{Batch ion exchange studies}

Ion-exchange equilibrium data. To gain further insight into the $\mathrm{Cr}_{2} \mathrm{O}_{7}{ }^{2-}$ sorption properties of the MOR-1-HA material, we first performed batch ion exchange studies. The $\mathrm{Cr}_{2} \mathrm{O}_{7}{ }^{2-}$ ion exchange equilibrium data for MOR-1-HA composite are shown graphically in Fig. 5. The description of the data can be provided by the Langmuir model (fitting also can be done with the Freundlich model, see ESI Fig. S6 and Table S1 $\dagger) .{ }^{15}$ The sorption capacity is $242 \pm 17 \mathrm{mg} \mathrm{Cr}_{2} \mathrm{O}_{7}{ }^{2-}$ per g of MOR-1-HA (or 242/ 0.96-252 $\mathrm{mg} \mathrm{g}^{-1}$ of MOR-1, considering that MOR-1-HA contains $96 \%$ wt of MOR-1), which is well-comparable with the capacities of the best $\mathrm{Cr}(\mathrm{vI})$ sorbents. ${ }^{7,9}$ This sorption capacity is consistent with the absorption of $\sim 2.7 \pm 0.2$ moles of $\mathrm{Cr}_{2} \mathrm{O}_{7}{ }^{2-}$ per formula unit of the MOR-1, which is close to the expected maximum sorption capacity of the material $(3.0 \mathrm{~mol}$ per formula unit). The affinity of the MOR-1-HA for dichromate can

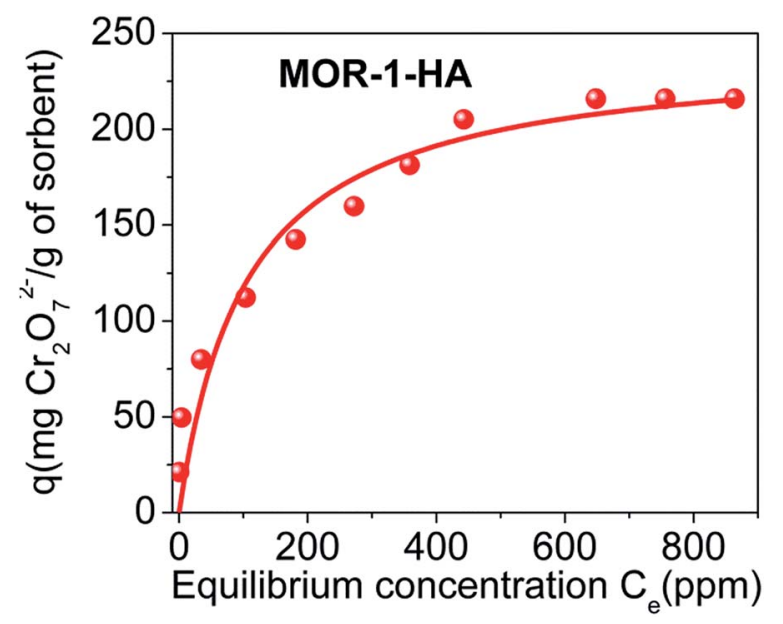

Fig. 5 Equilibrium $\mathrm{Cr}_{2} \mathrm{O}_{7}{ }^{2-}$ sorption data for MOR-1-HA material $(\mathrm{pH}$ $\sim 3$ ). The solid line represents the fitting of the data with the Langmuir model. be expressed in terms of the distribution coefficient $K_{\mathrm{d}}$ which is given by the equation

$$
K_{\mathrm{d}}=\frac{V\left[\left(C_{0}-C_{\mathrm{f}}\right) / C_{\mathrm{f}}\right]}{m}
$$

where $C_{0}$ and $C_{\mathrm{f}}$ are the initial and equilibrium concentration of $\mathrm{Cr}_{2} \mathrm{O}_{7}{ }^{2-}$ (ppm), respectively, $V$ is the volume $(\mathrm{mL})$ of the testing solution and $m$ is the amount of the ion exchanger $(\mathrm{g})$ used in the experiment. ${ }^{15}$ Values for $K_{\mathrm{d}}$ equal to or above $10^{4} \mathrm{~L} \mathrm{~g}^{-1}$ are considered excellent. The maximum $K_{d}^{\mathrm{Cr}_{2} \mathrm{O}_{7}}$ values for the MOR1-HA, obtained from the batch equilibrium studies, are in the range of (1.2-5.5) $\times 10^{4} \mathrm{~L} \mathrm{~g}^{-1}$, which reveal the exceptional affinity of this material for dichromate ions. We should also note that MOR-1-HA samples loaded with $\mathrm{Cr}_{2} \mathrm{O}_{7}{ }^{2-}$ can be easily regenerated by treating them with concentrated $\mathrm{HCl}$ solutions (1.2-4 M). The PXRD pattern of the regenerated MOF-1-HA is almost identical with that of as prepared MOR-1-HA material (Fig. 4A). The regenerated MOR-1-HA showed similar dichromate exchange capacity $\left(230-240 \mathrm{mg} \mathrm{g}^{-1}\right)$ as that of pristine material (more detailed regeneration studies were performed for the ion exchange columns, see below).

Kinetic studies. The kinetics of the $\mathrm{Cr}_{2} \mathrm{O}_{7}{ }^{2-}$ exchange of the MOR-1-HA composite was also studied. The results indicate that the capture of $\mathrm{Cr}_{2} \mathrm{O}_{7}{ }^{2-}$ by the composite was remarkably fast, as indicated by UV-Vis and ICP-MS data (Fig. 6). Within only $1 \mathrm{~min}$ of solution/composite contact, $\sim 94.2 \%$ of the initial $\mathrm{Cr}_{2} \mathrm{O}_{7}{ }^{2-}$ amount $\left(C_{0}=21.6 \mathrm{ppm}, \mathrm{pH} \sim 3\right)$ was removed by the solution. After $3 \mathrm{~min}$ of solution/composite contact, the $\mathrm{Cr}(\mathrm{vI})$ ion exchange almost reached its equilibrium with $\sim 97.5 \%$ removal capacity. These kinetic data can be fitted (Fig. 6B, inset) with the Lagergren's first-order equation

$$
q_{t}=q_{\mathrm{e}}\left[1-\exp \left(-K_{\mathrm{L}} t\right)\right]
$$

where $q_{\mathrm{e}}=$ the amount $\left(\mathrm{mg} \mathrm{g}^{-1}\right)$ of metal ion absorbed in equilibrium, $K_{\mathrm{L}}=$ the Lagergren or first-order rate constant (fitting parameters: $q_{\mathrm{e}}=21.1 \pm 0.4 \mathrm{mg} \mathrm{g}^{-1}, K_{\mathrm{L}}=3.3 \pm 0.1$ $\left.\min ^{-1}, R^{2}=0.90\right) .{ }^{16}$ From these data, it is clear that the ordered highly porous structure of MOR-1-HA facilitating the diffusion of ions in and out of pores and the presence of protonated amine-functional groups strongly interacting with $\mathrm{Cr}(\mathrm{vI})$ (see theoretical studies below) result in a sorbent with exceptionally rapid sorption kinetics.

Variable pH studies. Although the $\mathrm{Cr}(\mathrm{vI})$ ion exchange studies for MOR-1-HA were mainly performed at $\mathrm{pH} \sim 3$ in order to evaluate the capability of the sorbent to operate under acidic conditions usually present in industrial waste, the composite material is capable of absorbing $\mathrm{Cr}(\mathrm{vI})$ from solutions of a relatively wide $\mathrm{pH}$ range (1-8), Fig. 7. Specifically, it shows 91-98\% total $\mathrm{Cr}$ removal capacities in $\mathrm{pH} \sim 3-8$ (initial dichromate concentration $=21.6 \mathrm{ppm})$, whereas it retains high Cr removal capability even under highly acidic conditions $(\sim 81$ and $90 \%$ removal capacities at $\mathrm{pH} \sim 1$ and 2 , respectively).

Selectivity studies. $\mathrm{Cr}(\mathrm{vI})$ bearing industrial effluent contains a number of competitive anions, such as $\mathrm{Cl}^{-}, \mathrm{NO}_{3}{ }^{-}, \mathrm{Br}^{-}$and $\mathrm{SO}_{4}{ }^{2-}$, in high concentrations. Thus, we have performed competitive $\mathrm{Cr}_{2} \mathrm{O}_{7}{ }^{2-} / \mathrm{Cl}^{-}, \mathrm{Cr}_{2} \mathrm{O}_{7}{ }^{2-} / \mathrm{Br}^{-}, \mathrm{Cr}_{2} \mathrm{O}_{7}{ }^{2-} / \mathrm{NO}_{3}{ }^{-}$and 

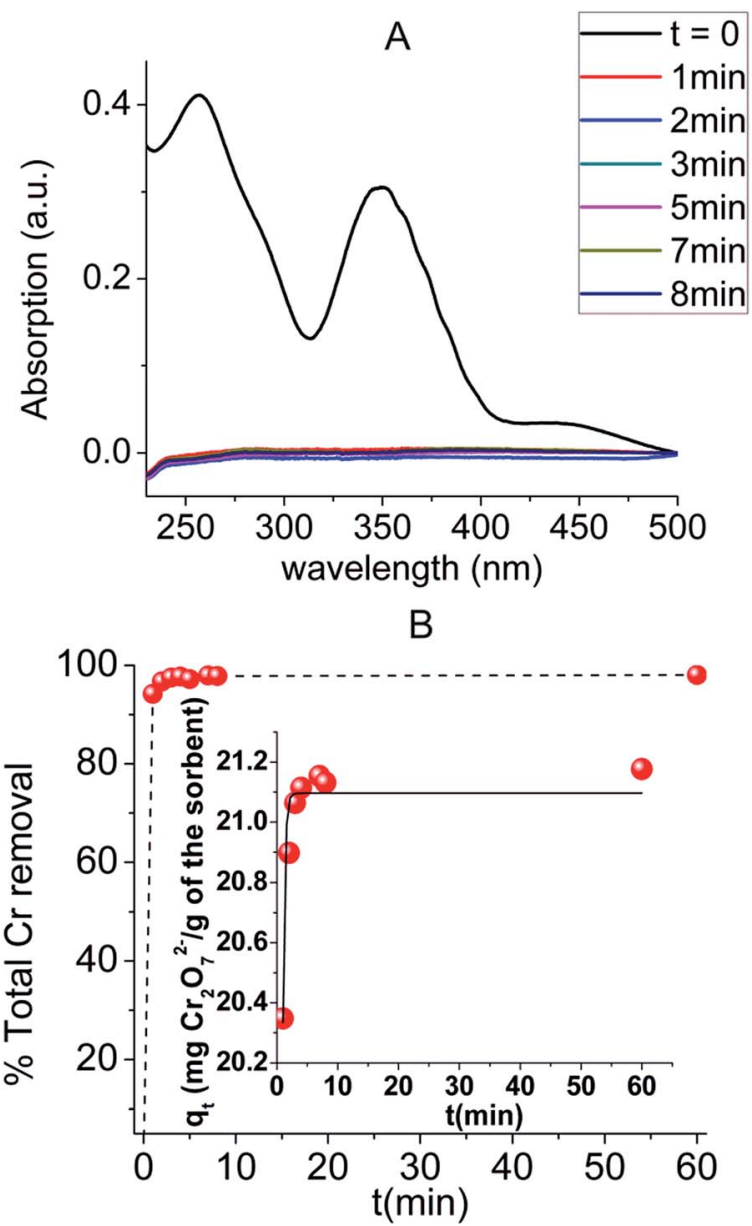

Fig. 6 (A) Selected UV-Vis data from the kinetic experiments (initial

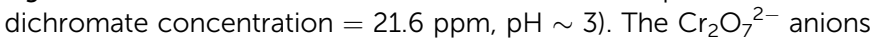
are not detectable after the sorption process with UV-Vis and thus, the dichromate concentrations of the solutions were determined by ICPMS. (B) \% Total $\mathrm{Cr}$ removal (determined by ICP-MS data) by MOR-1HA vs. time (min). Inset graph: fitting of the kinetics data with the Lagergren's first-order equation.

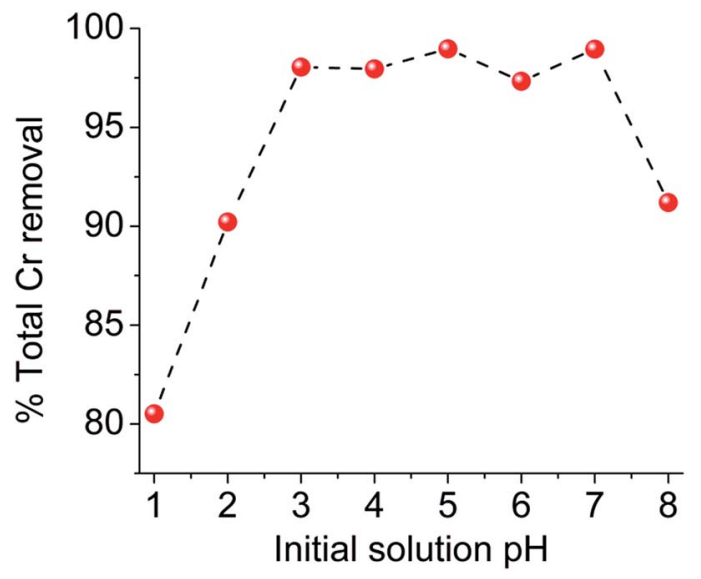

Fig. 7 \% Total $\mathrm{Cr}$ removal (determined by ICP-MS data) by MOR-1-HA vs. $\mathrm{pH}$ (initial dichromate concentration $=21.6 \mathrm{ppm}$ ). For $\mathrm{pH} \geq 9$, dissolution of the composite was observed.
$\mathrm{Cr}_{2} \mathrm{O}_{7}{ }^{2-} / \mathrm{SO}_{4}{ }^{2-}$ sorption experiments for MOR-1-HA. We have observed an exceptional ability of MOR-1-HA to absorb $\mathrm{Cr}_{2} \mathrm{O}_{7}{ }^{2-}$ (initial concentration $=54 \mathrm{ppm}, \mathrm{pH} \sim 3$ ) almost quantitatively (81.6-97.6\% dichromate removal capacity) and very high $K_{\mathrm{d}}^{\mathrm{Cr}_{2} \mathrm{O}_{7}}$ $\left(4.4 \times 10^{3}\right.$ to $\left.4 \times 10^{4} \mathrm{~L} \mathrm{~g}^{-1}\right)$ in the presence of a tremendous (up to 1000 -fold) excess of $\mathrm{Cl}^{-}, \mathrm{Br}^{-}$, or $\mathrm{NO}_{3}{ }^{-}$, which indicates the very high selectivity of MOR-1-HA for $\mathrm{Cr}_{2} \mathrm{O}_{7}{ }^{2-}$ against these anions (Fig. S7 and Table $\mathrm{S} 2 \dagger$ ). $\mathrm{SO}_{4}{ }^{2-}$ as a bivalent anion is expected to be stronger competitor than monovalent anions for dichromate anion exchange. Nevertheless, even with relatively large (20-80-fold) excess of $\mathrm{SO}_{4}{ }^{2-}$, MOR-1-HA retained a very good $\mathrm{Cr}_{2} \mathrm{O}_{7}{ }^{2-}$ removal efficiency (40-68\%) and relatively high $K_{\mathrm{d}}^{\mathrm{Cr}_{2} \mathrm{O}_{7}}$ values (up to $2.1 \times 10^{3} \mathrm{~mL} \mathrm{~g}^{-1}$ ) (Fig. S7 and Table S2 $\dagger$ ). By plotting $\log \left(K_{\mathrm{d}}^{\mathrm{Cr}_{2} \mathrm{O}_{7}}\right)$ vs. $\log \left(C_{\mathrm{B}}\right)\left(C_{\mathrm{B}}=\right.$ concentration of $\mathrm{Cl}^{-}, \mathrm{Br}^{-}$, $\mathrm{NO}_{3}{ }^{-}$or $\mathrm{SO}_{4}{ }^{2-}$ ions in mol L $\left.{ }^{-1}\right)$, large selectivity coefficients ${ }^{15}$ of MOR-1-HA for $\mathrm{Cr}_{2} \mathrm{O}_{7}{ }^{2-}$ against $\mathrm{Cl}^{-}, \mathrm{Br}^{-}, \mathrm{NO}_{3}{ }^{-}$and $\mathrm{SO}_{4}{ }^{2-}$ were observed (selectivity coefficient $K\left(\mathrm{Cr}_{2} \mathrm{O}_{7}{ }^{2-} / \mathrm{Cl}^{-}\right)=200$, $K\left(\mathrm{Cr}_{2} \mathrm{O}_{7}{ }^{2-} / \mathrm{Br}^{-}\right)=229, K\left(\mathrm{Cr}_{2} \mathrm{O}_{7}{ }^{2-} / \mathrm{NO}_{3}{ }^{-}\right)=224, K\left(\mathrm{Cr}_{2} \mathrm{O}_{7}{ }^{2-} / \mathrm{SO}_{4}{ }^{2-}\right)$ $=159, \mathrm{ESI} \dagger$ ).

Comparative batch ion-exchange studies. For comparison, we have also performed batch $\mathrm{Cr}_{2} \mathrm{O}_{7}{ }^{2-}$ sorption studies (at $\mathrm{pH} \sim$ 3) for (a) protonated MOR-1 $\left[\mathrm{Zr}_{6} \mathrm{O}_{4}(\mathrm{OH})_{4}\left(\mathrm{NH}_{3}{ }^{+}-\mathrm{BDC}\right)_{6}\right] \mathrm{Cl}_{6}$ (MOR-1 treated with $\mathrm{HCl} 4 \mathrm{M}$ ), (b) non-protonated MOR-1 $\left[\mathrm{Zr}_{6} \mathrm{O}_{4}(\mathrm{OH})_{4}^{-}\right.$ $\left.\left(\mathrm{NH}_{2}-\mathrm{BDC}\right)_{6}\right]$ (prepared without adding acid in the reaction mixture) and (c) UiO-66 MOF $\left(\left[\mathrm{Zr}_{6} \mathrm{O}_{4}(\mathrm{OH})_{4}(\mathrm{BDC})_{6}\right]\right)-\mathbf{H A}$ composite. The results indicate that the sorption capacities of protonated MOR-1 and non-protonated MOR-1 are similar to each other $\left(247 \pm 10\right.$ and $267 \pm 23 \mathrm{mg} \mathrm{g}^{-1}$ respectively, Fig. S6 and Table S1 $\dagger$ ) and also close to that of MOR-1-HA composite, whereas the sorption capacity $\left(129 \pm 18 \mathrm{mg} \mathrm{g}^{-1}\right)$ of UiO-66-HA is almost half of that for MOR-1-HA. The efficiency, however, of protonated MOR-1 and MOR-1-HA for sorption of dichromate in relatively low initial concentrations, as revealed by the $K_{d}^{\mathrm{Cr}_{2} \mathrm{O}_{7}}$ values, is significantly higher than that of non-protonated MOR-1 and UiO-66-HA. Specifically, UiO-66-HA and non-protonated MOR-1 materials show $K_{\mathrm{d}}^{\mathrm{Cr}_{2} \mathrm{O}_{7}}$ values of 2.3 and $6.5 \times 10^{3} \mathrm{~L} \mathrm{~g}^{-1}$, respectively, for initial dichromate concentration of $\sim 21.6 \mathrm{ppm}$ (Fig. 8), which are one order of magnitude less than those $(\sim 5.5 \times$ $10^{4} \mathrm{~L} \mathrm{~g}^{-1}$ ) for MOR-1-HA and protonated MOR-1 samples (Fig. 8).

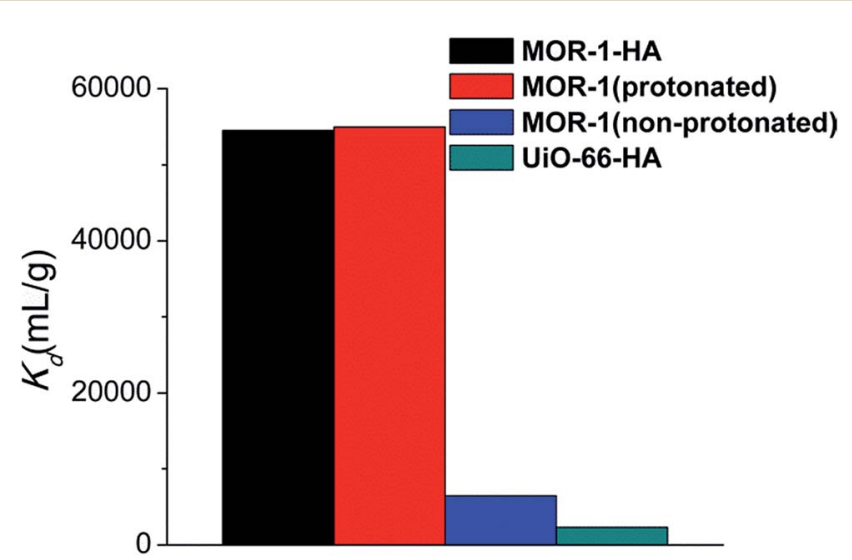

Fig. $8 \quad K_{d}$ values for MOR-1-HA, MOR-1 (protonated), MOR-1 (nonprotonated) and UiO-66-HA (initial dichromate concentration $=21.6$ ppm). 
As the above results revealed, both protonated and nonprotonated MOR-1 materials display similar maximum sorption capacities, since at the acidic environment the $\mathrm{NH}_{2}$-groups will be eventually protonated and the inserted $\mathrm{Cl}^{-}$can be exchanged by dichromate anions. However, at low initial $\mathrm{Cr}(\mathrm{vI})$ concentrations the materials pre-treated with acid (i.e. protonated MOR-1 and MOR-1-HA) are much more effective for the sorption of $\mathrm{Cr}(\mathrm{vI})$ as revealed by their much higher $K_{\mathrm{d}}$ values compared to that of MOR-1 used without any pre-treatment (non-protonated MOR-1). Presumably, the pre-existence of exchangeable $\mathrm{Cl}^{-}$ anions in the protonated materials enhances the kinetics of the $\mathrm{Cr}(\mathrm{vI})$ sorption, whereas the $\mathrm{Cr}(\mathrm{vI})$ sorption by the non-protonated MOR is a slower two-step process involving first protonation of the amine-sites/insertion of $\mathrm{Cl}^{-}$anions and then exchange of $\mathrm{Cl}^{-}$by $\mathrm{Cr}(\mathrm{vI})$ species. The enhancement of sorption kinetics is particularly important in the case of low initial $\mathrm{Cr}(\mathrm{vI})$ concentrations, which are not as effective as the high $\mathrm{Cr}(\mathrm{vI})$ levels at shifting the ion-exchange equilibrium towards the $\mathrm{Cr}(\mathrm{vI})$-containing material. The above explanation is supported by the kinetic study of the $\mathrm{Cr}_{2} \mathrm{O}_{7}{ }^{2-}$ exchange of the nonprotonated MOR-1 (Fig. S8†) using a relatively low initial dichromate concentration (21.6 ppm, $\mathrm{pH} \sim 3$ ). The results showed that after $1 \mathrm{~min}$ of solution/MOR contact only $24 \%$ $\mathrm{Cr}_{2} \mathrm{O}_{7}{ }^{2-}$ removal is achieved, whereas even after $60 \mathrm{~min}$ of reaction significant amount of dichromate remains in the solution ( $\sim 76 \% \mathrm{Cr}_{2} \mathrm{O}_{7}{ }^{2-}$ removal). These data are in contrast with the corresponding kinetic results for MOR-1-HA which indicated almost quantitative sorption of dichromate anions within only $1 \mathrm{~min}$ of solution/composite contact (Fig. 6). Furthermore, fitting of the kinetic data for the non-protonated MOR-1 with the Lagergren's first order equation revealed a rate constant of $0.55 \pm 0.14 \mathrm{~min}^{-1}$ (Fig. S8 $\dagger$ ), which is six-times smaller than that for the $\mathrm{Cr}_{2} \mathrm{O}_{7}{ }^{2-}$ sorption by MOR-1-HA. This improvement of kinetics via the protonation of the material is the key for its substantially higher column sorption efficiency compared to that of non-protonated sorbent (see below).

\section{Column ion exchange studies}

The next step in our investigations was the study of the column $\mathrm{Cr}(\mathrm{vI})$ sorption properties of the MOR-1-HA material. At this point, we should mention that efforts to use as-prepared MOR-1 (even after mixing it with inert materials such as sand) in columns, were unsuccessful since MOR-1 forms fine suspensions in water that pass through the column (Fig. 9A). In contrast, MOR-1-HA composite is kept fixed in the column (Fig. 9B) and thus, it could be successfully employed for column sorption studies. The stationary phase in the columns was a mixture of MOR-1-HA and sand, a common inexpensive and inert material typically used in columns. The use of such mixtures instead of the pure composite has several advantages: (a) the pieces of the composite material are immobilized (not disturbed and moved by the water flow) and separated by particles of sand thus ensuring a continuous water flow through the column, (b) the pressure exerted by water on the composite will be reduced since part of this pressure will be absorbed by the second material (sand) and (c) mixing the composite

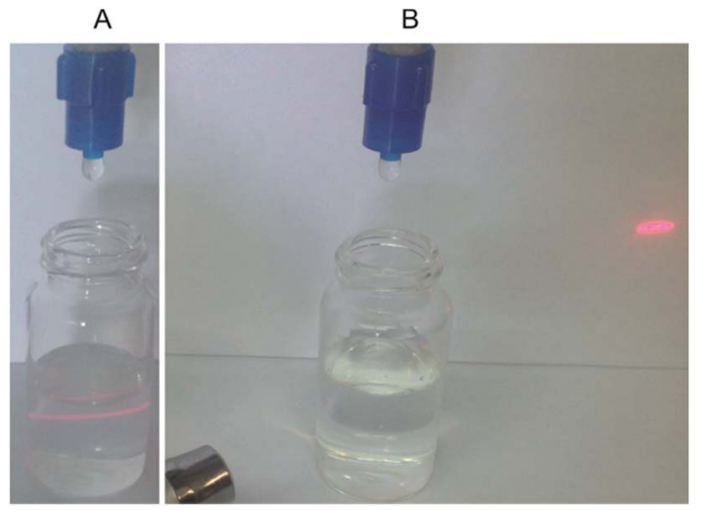

Fig. 9 (A) As-prepared MOR-1/sand column is washed with $\mathrm{HCl}$ acid (for protonation or regeneration of the sorbent) and then deionized water (to remove excess acid). As a result, MOR-1 is coming through the column, since it forms a fine suspension as confirmed by the test with the laser beam. (B) The effluent collected after washing the MOR1-HA/sand column with $\mathrm{HCl}$ acid and deionized water is a clear solution (as confirmed by the test with the laser beam).

material with a very low cost material such as sand is economically attractive. We should note that no clogging of MOR-1-HA/sand columns was observed after passing several liters of solutions through them. Remarkably, we found that stationary phases containing only $\sim 1 \%$ wt of MOR-1-HA and $99 \%$ wt sand are very effective for the removal of either high or low concentration $\mathrm{Cr}(\mathrm{vI})$ from aqueous solutions of various compositions. It can be seen that highly concentrated dichromate solution $\left(C_{0}=1075 \mathrm{ppm}, \mathrm{pH} \sim 3\right)$ is decolorized after passing it through the MOR-1-HA/sand column and also the stationary phase changed color from cream white to orange (red)-brown after the sorption of significant amount of $\mathrm{Cr}_{2} \mathrm{O}_{7}{ }^{2-}$ anions (Fig. 10A and C). The sorbent can be easily regenerated by washing it with $\mathrm{HCl}$ solution (1.2-4 M) (Fig. 10B). The regeneration can be visually observed by the restoration of the cream white color of the initial MOR-1-HA/sand stationary phase (Fig. 10D).

Detailed column sorption studies were performed with $\mathrm{Cr}_{2} \mathrm{O}_{7}{ }^{2-}$ solutions of relatively low or trace concentrations, which cannot be treated with common methods such as precipitation. Specifically, column sorption of a solution $(\mathrm{pH} \sim$ 3) of dichromate anions with concentration of $6 \mathrm{ppm}$ results in total $\mathrm{Cr}$ concentrations $\leq 47 \mathrm{ppb}$, which are below than the USA-EPA and EU allowed limits for total $\mathrm{Cr}$ in water, for 80 bed volumes (bed volume $=[$ bed height $(\mathrm{cm}) \times$ cross sectional area $\left.\left(\mathrm{cm}^{2}\right)\right] \mathrm{mL}$ ) of the effluent (Fig. 11A). After regeneration, a breakthrough curve almost identical to that of the first run was obtained, whereas only a small decrease ( $\sim 6$ bed volumes) of the breakthrough capacity was observed after a fourth run of the column (Fig. 11A).

Column sorption studies have been also conducted with dichromate solutions ( $\mathrm{pH} \sim 3, C=7 \mathrm{ppm}$ ) containing 100-fold excess of each of $\mathrm{Cl}^{-}, \mathrm{Br}^{-}$and $\mathrm{NO}_{3}^{-}$anions. Still, the MOR-1HA/sand column shows significant breakthrough capacity $(\sim 43$ bed volumes) (Fig. S9†), a value which remains exactly the same after its regeneration. 
A

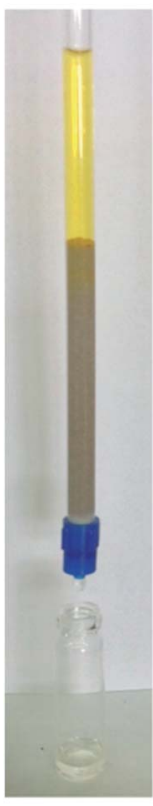

B

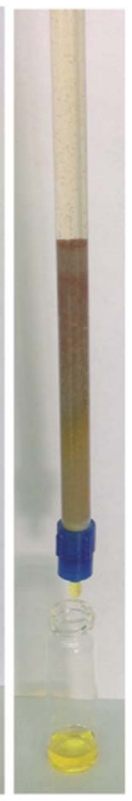

C

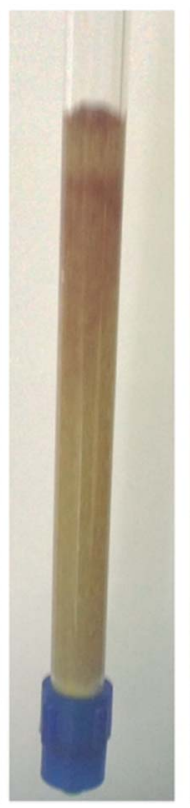

D

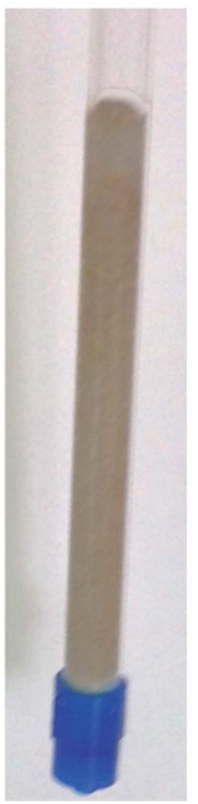

Fig. 10 (A) Decolouration of $\mathrm{C}_{2} \mathrm{O}_{7}{ }^{2-}$ solution (initial concentration $=1075 \mathrm{ppm}, \mathrm{pH} \sim 3$ ) with an ion-exchange column of MOR-1-A/sand $(0.05: 5 \mathrm{~g})$. (B) Regeneration of the $\mathrm{Cr}_{2} \mathrm{O}_{7}{ }^{2-}$-loaded column by washing it with $4 \mathrm{M} \mathrm{HCl}$ solution. (C) Column with the stationary phase saturated with $\mathrm{Cr}_{2} \mathrm{O}_{7}{ }^{2-}$. (D) Column after the regeneration process.

Because of the excellent $\mathrm{Cr}_{2} \mathrm{O}_{7}{ }^{2-}$-column sorption properties described above, we decided to examine the applicability of MOR1-HA/sand column for remediation of real-world water samples intentionally contaminated by trace concentrations of $\mathrm{Cr}_{2} \mathrm{O}_{7}{ }^{2-}$. Specifically, we tested the performance of this ion exchange column for the decontamination of natural spring water solutions (with the $\mathrm{pH}$ of the solution adjusted to $\sim 3$ ) to which trace levels of $\mathrm{Cr}_{2} \mathrm{O}_{7}{ }^{2-}$ (total $\mathrm{Cr}$ concentration analysed with ICP-MS $\sim 450$ $\mathrm{ppb}$ ) were added. Note that the tested water solutions contain 27 , 28 and 305 -fold excess of $\mathrm{SO}_{4}{ }^{2-}, \mathrm{NO}_{3}{ }^{-}$and $\mathrm{Cl}^{-}$anions, respectively, compared to the initial concentration of dichromate anions. The results indicated that at least 21 samples (bed volumes) collected after running the column three times (with regeneration of the column after each run) contain total $\mathrm{Cr}$ in a concentration $\leq 1 \mathrm{ppb}$, i.e. well below the allowed USA-EPA and EU levels for total $\mathrm{Cr}$ in water, Fig. 11B. We should also mention that no $\mathrm{Zr}$ was detected in the effluent samples (by ICP-MS analysis), thus excluding MOR-1-HA leaching from the column.

Finally, we investigated the performance of MOR-1-CA/sand column for dichromate sorption. The results revealed a breakthrough capacity of only 15 bed volumes (initial dichromate concentration $=6 \mathrm{ppm}, \mathrm{pH} \sim 3$, MOR-1-CA/sand $=0.05: 5 \mathrm{~g}$, Fig. S10†) for this column, which is $\sim 80 \%$ smaller than that of the MOR-1-HA/sand column (77 bed volumes, Fig. 11a). These data reflect the significantly enhanced $\mathrm{Cr}(\mathrm{vI})$ sorption kinetics for the protonated material (i.e. MOR-1-HA), as discussed above.

\section{Mechanism of $\mathrm{Cr}(\mathrm{vI})$-sorption}

To provide an explanation for the remarkable selectivity of the protonated amino functionalized material for dichromate

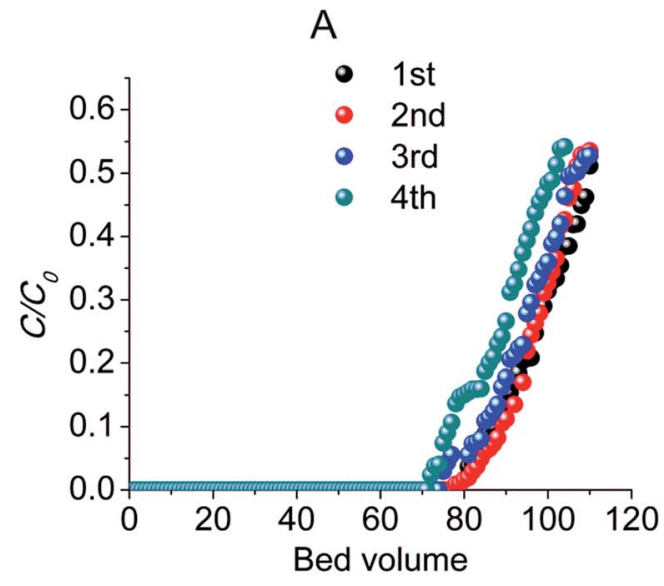

$B$

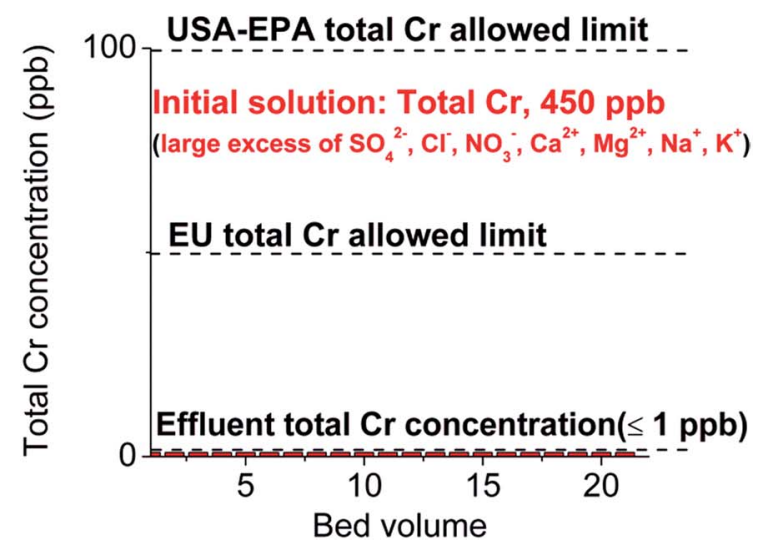

Fig. 11 (A) Breakthrough curves for four column ion exchange runs $\left(\mathrm{C}=\right.$ concentration of the effluent, $\mathrm{C}_{0}=$ initial $\mathrm{Cr}_{2} \mathrm{O}_{7}{ }^{2-}$ concentration

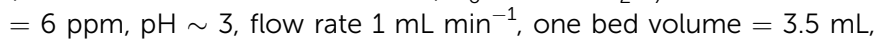
stationary phase MOR-1-A/sand $=0.05: 5 \mathrm{~g}$ ). (B) Total $\mathrm{Cr}$ concentration vs. bed volume (each bed volume $=3.5 \mathrm{~mL}$ ) of natural spring water, to which trace $\mathrm{Cr}(\mathrm{VI})$ was added (initial total $\mathrm{Cr}$ concentration $\sim$ $450 \mathrm{ppb}, \mathrm{pH}$ adjusted to 3), after passing the solution through an ionexchange column of MOR-1-A/sand $(0.05: 5 \mathrm{~g})$.

anions, we calculated the interaction energies of $\mathrm{Cr}_{2} \mathrm{O}_{7}{ }^{2-}$, $\mathrm{HOCrO}_{3}{ }^{-}, \mathrm{Cl}^{-}, \mathrm{Br}^{-}, \mathrm{NO}_{3}{ }^{-}, \mathrm{HOSO}_{3}{ }^{-}$and $\mathrm{SO}_{4}{ }^{2-}$ anions with the $\left[\mathrm{Zr}_{6} \mathrm{O}_{4}(\mathrm{OH})_{4}\left(\mathrm{NH}_{3}{ }^{+}-\mathrm{BDC}\right)_{6}\right] \mathrm{Cl}_{6}-\mathrm{HA}(\mathbf{M O R - 1}-\mathrm{HA})$, represented by the simple anilinium Ar- $\mathrm{NH}_{3}{ }^{+}$cation, employing DFT methods $(\mathrm{ESI} \dagger)$. The calculated interaction energies along with selected structural parameters of the respective associations are compiled in Table 1, while the optimized geometries and a brief description of them are given in the ESI (Fig. S11†).

Interestingly, our calculations indicate that $\mathrm{SO}_{4}{ }^{2-}$ abstracts a $\mathrm{NH}_{3}{ }^{+}$proton from the $\mathrm{Ar}-\mathrm{NH}_{3}{ }^{+}$cation yielding $\mathrm{HOSO}_{3}{ }^{-}$anions via an exothermic process (exothermicity of $-26.7 \mathrm{kcal} \mathrm{mol}^{-1}$ ). Thus, in $\mathrm{Cr}_{2} \mathrm{O}_{7}{ }^{2-} / \mathrm{SO}_{4}{ }^{2-}$ competition ion-exchange reactions with MOR-1-HA, the actual competitor for dichromate exchange was $\mathrm{HOSO}_{3}{ }^{-}$. The latter as a monovalent anion is expected to be less competitive than $\mathrm{SO}_{4}{ }^{2-}$ for $\mathrm{Cr}(\mathrm{vI})$ sorption. This can be one of the reasons for the relatively high selectivity of MOR-1-HA for $\mathrm{Cr}(\mathrm{vI})$ vs. $\mathrm{SO}_{4}{ }^{2-}$, which was experimentally observed. 
Table 1 Interaction energies, IE (in $\mathrm{kcal} \mathrm{mol}^{-1}$ ) and selected structural parameters (bond lengths $R$ in $\AA$, bond angles $\angle$ in degrees) for the Ar$\mathrm{NH}_{3}{ }^{+} \ldots \mathrm{A}\left(\mathrm{A}=\mathrm{Cl}^{-}, \mathrm{Br}^{-}, \mathrm{NO}_{3}{ }^{-}, \mathrm{HOSO}_{3}{ }^{-}, \mathrm{HOCrO}_{3}{ }^{-}, \mathrm{Cr}_{2} \mathrm{O}_{7}{ }^{2-}\right)$ associations in aqueous solutions calculated by the wB97XD/Def2-TZVPPD/ PCM computational protocol

\begin{tabular}{lrlll}
\hline Anion & \multicolumn{1}{c}{ IE } & $R(\mathrm{O} \cdots \mathrm{H}-\mathrm{N})$ & $R(\mathrm{~N}-\mathrm{H})$ & $\angle \mathrm{O} \cdots \mathrm{H}-\mathrm{N}$ \\
\hline $\mathrm{Cl}^{-}$ & 11.7 & 1.942 & 1.070 & 176.1 \\
$\mathrm{Br}^{-}$ & 9.9 & 2.139 & 1.061 & 176.0 \\
$\mathrm{NO}_{3}{ }^{-}$ & 13.3 & 1.597 & 1.071 & 175.7 \\
$\mathrm{HOSO}_{3}{ }^{-}$ & 12.0 & 1.660 & 1.055 & 166.6 \\
$\mathrm{HOCrO}_{3}{ }^{-}$ & 12.6 & 1.672 & 1.020 & 110.3 \\
$\mathrm{Cr}_{2} \mathrm{O}_{7}{ }^{2-}$ & & 2.142 & 1.052 & 159.4 \\
& 15.5 & 1.637 & 1.024 & 127.9 \\
& & & 1.055 & 163.1
\end{tabular}

Among the anions studied, the $\mathrm{Cr}_{2} \mathrm{O}_{7}{ }^{2-}$ anion shows the strongest interactions $\left(15.6 \mathrm{kcal} \mathrm{mol}^{-1}\right)$. However, the estimated values of the interaction energies for the $\mathrm{Ar}-\mathrm{NH}_{3}{ }^{+} \cdots \mathrm{A}\left(\mathrm{A}=\mathrm{Cl}^{-}\right.$, $\mathrm{Br}^{-}, \mathrm{NO}_{3}{ }^{-}, \mathrm{HOSO}_{3}{ }^{-}, \mathrm{HOCrO}_{3}{ }^{-}, \mathrm{Cr}_{2} \mathrm{O}_{7}{ }^{2-}$ ) associations could not fully explain the high selectivity of the material under study towards $\mathrm{Cr}_{2} \mathrm{O}_{7}{ }^{2-}$ anions and the limited selectivity for the rest of the competitive anions in the series. Therefore, this selectivity could be due to much stronger interactions between the $\mathrm{Cr}_{2} \mathrm{O}_{7}{ }^{2-}$ anions and the $\mathrm{Ar}-\mathrm{NH}_{3}{ }^{+}$cation. Experimental IR-data indicate that the amine-deformation band is significantly redshifted for MOR-1-HA@Cr(VI) (1565 $\mathrm{cm}^{-1}$ ) compared to that for pristine MOR-1-HA (1590 $\mathrm{cm}^{-1}$ ) and as prepared MOR-1 (1580 $\mathrm{cm}^{-1}$ ) samples (Fig. 4C and S5 $\dagger$ ). ${ }^{17 \boldsymbol{a}, \boldsymbol{b}}$ Furthermore, the IR peak at $1620 \mathrm{~cm}^{-1}$ (assigned to ring stretching vibration) in the spectrum of MOR-1-HA@Cr(VI), which is also present in the IR spectrum of non-protonated MOR but it is not shown or is of very weak intensity in the spectrum of MOR-1-HA, is indicative of an $\mathrm{NH}_{2}$ - rather than $\mathrm{NH}_{3}{ }^{+}$-containing phenyl ring (Fig. S5 $\dagger$ ). ${ }^{17 c}$ In addition, the solid-state UV-Vis spectrum (Fig. S12 $\dagger$ ) for MOR-1-HA@Cr(VI) reveals a broad feature (around $500 \mathrm{~nm}$ ) in the visible region (not shown in the spectrum of as-prepared MOR-1 and MOR-1-HA) which may be due to charge transfer from the electron rich $\mathrm{NH}_{2}-\mathrm{BDC}^{2-}$ ligand to $\mathrm{Cr}(\mathrm{vI})$ species (LMCT). The above support strong $\mathrm{NH}_{2}-\mathrm{Cr}(\mathrm{vI})$ interactions in MOR-1-HA@Cr(VI).

We thus suggest the transformation of dichromate to $\mathrm{Cr}^{\mathrm{VI}} \mathrm{O}_{3}$ species which in turn forms the tetrahedral $\left[\left(\mathrm{Ar}-\mathrm{NH}_{2}\right) \mathrm{CrO}_{3}\right]$ complex. ${ }^{18}$ To test this hypothesis, the equilibrium geometry of the $\left[\left(\mathrm{Ar}-\mathrm{NH}_{2}\right) \mathrm{CrO}_{3}\right]$ complex in aqueous solution was optimized at the wB97XD/Def2-TZVPPD level of theory, Fig. 12. The formation of such complex may be promoted by the significant acidity of anilinium ion (the $\mathrm{p} K_{\mathrm{a}}$ of the anilinium ion is lower than 4.6). Anilinium may interact with the bridging $\mathrm{O}$ atom (nucleophilic center) of $\mathrm{Cr}_{2} \mathrm{O}_{7}{ }^{2-}$ enforcing the rupture of a $\mathrm{O}-\mathrm{Cr}$ bridging bond with concomitant coordination of aniline to the $\mathrm{CrO}_{3}$ fragment and formation of $\mathrm{HOCrO}_{3}{ }^{-}$anion. The latter subsequently re-equilibrates to produce $\mathrm{Cr}_{2} \mathrm{O}_{7}{ }^{2-}$ :

$$
\begin{gathered}
\mathrm{Ar}-\mathrm{NH}_{3}{ }^{+}+\mathrm{Cr}_{2} \mathrm{O}_{7}{ }^{2-} \rightarrow\left(\mathrm{Ar}-\mathrm{NH}_{2}\right) \mathrm{CrO}_{3}+\mathrm{HOCrO}_{3}{ }^{-} \\
2 \mathrm{HOCrO}_{3}^{-} \rightarrow \mathrm{Cr}_{2} \mathrm{O}_{7}^{2-}+\mathrm{H}_{2} \mathrm{O}
\end{gathered}
$$
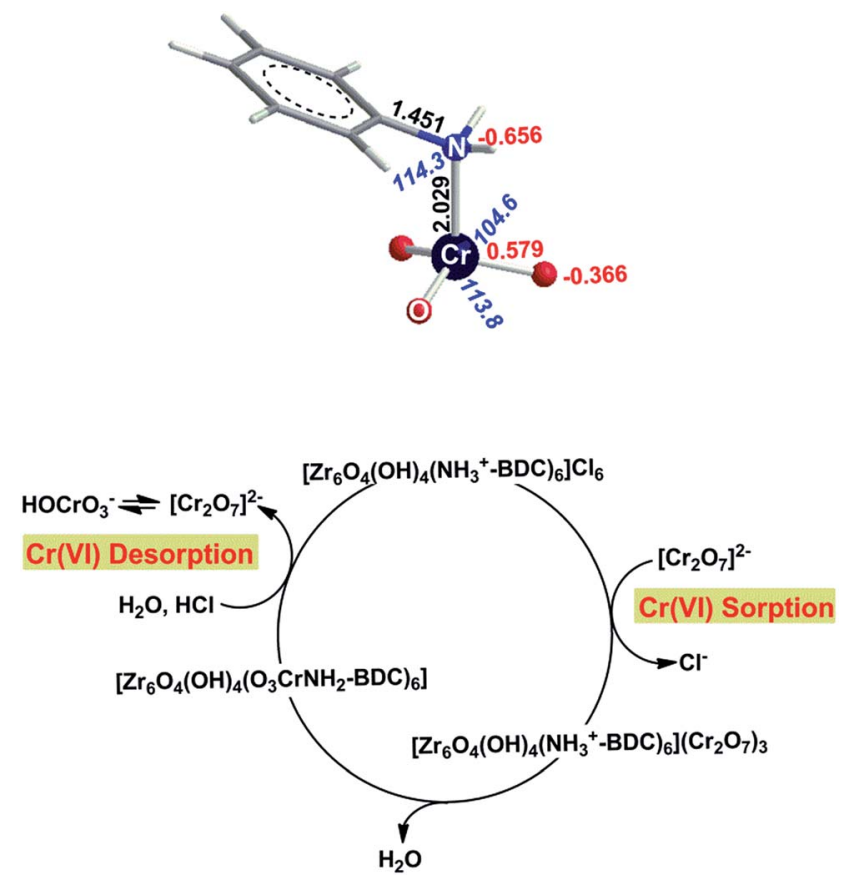

Fig. 12 Top: Equilibrium geometry of the $\left(\mathrm{Ar}-\mathrm{NH}_{2}\right) \mathrm{CrO}_{3}$ complex in aqueous solution optimized at the wB97XD/Def2-TZVPPD level of theory along with selected structural parameters (bond lengths in $\AA$ and bond angles marked in blue in degrees) and the natural atomic charges (marked in red) on the donor atoms constituting the coordination sphere and the central $\mathrm{Cr}$ atom. Bottom: Suggested mechanism for the $\mathrm{Cr}(\mathrm{vl})$ sorption and desorption.

The condensation of the $\mathrm{HOCrO}_{3}{ }^{-}$anion to form $\mathrm{Cr}_{2} \mathrm{O}_{7}{ }^{2-}$ is particularly an enthalpy driven reaction with a dimerization constant $K=159$ at standard conditions. ${ }^{19}$

The formation of the $\left(\mathrm{Ar}-\mathrm{NH}_{2}\right) \mathrm{CrO}_{3}$ complex is an almost thermoneutral process, the endothermicity found to be $1.8 \mathrm{kcal}$ $\mathrm{mol}^{-1}$. The presence of six $\mathrm{NH}_{3}^{+}$functional groups per $\mathrm{Zr}_{6}$ cluster affords six moles of the $\left(\mathrm{Ar}-\mathrm{NH}_{2}\right) \mathrm{CrO}_{3}$ complex, thus accounting well for the experimentally observed sorption of $\sim 3$ moles of $\mathrm{Cr}_{2} \mathrm{O}_{7}{ }^{2-}$ per formula unit of the MOR (Fig. 12).

Note that oxochromium(vi)-amine complexes are well-known compounds and many of them have been used as oxidants in organic synthesis. ${ }^{\mathbf{2 0}}$ The brick-red colour of the oxochromium(vi)-amine complexes ${ }^{20}$ could account well for the change of colour from cream white to orange (red)-brown of the MOR1-HA sorbent observed experimentally.

The regeneration of the MOR-1-HA columns by treating them with concentrated $\mathrm{HCl}$ solutions (1.2-4 M) can be easily explained by the acidic hydrolysis of the $\left(\mathrm{Ar}-\mathrm{NH}_{2}\right) \mathrm{CrO}_{3}$ complex

$$
\left[\left(\mathrm{Ar}-\mathrm{NH}_{2}\right) \mathrm{CrO}_{3}\right]+\mathrm{H}_{2} \mathrm{O} \rightarrow \mathrm{Ar}-\mathrm{NH}_{3}{ }^{+}+\mathrm{HOCrO}_{3}{ }^{-}
$$

with concomitant dimerization of $\mathrm{HOCrO}_{3}{ }^{-}$to $\mathrm{Cr}_{2} \mathrm{O}_{7}{ }^{2-}$ (Fig. 12). The exothermicity of the hydrolysis is predicted to be $30.5 \mathrm{kcal} \mathrm{mol}^{-1}$ at the wB97XD/Def2-TZVPPD level. The estimated binding energy of the aniline ligand with the $\mathrm{CrO}_{3}$ moiety is $34.4 \mathrm{kcal} \mathrm{mol}^{-1}$, while the negative natural atomic 
charge on the coordinated $\mathrm{N}$ donor atom renders the $\mathrm{N}$ atom susceptible to electrophilic attack by the $\mathrm{H}^{+}$ions, which is transformed to ammonium $\mathrm{NH}_{3}{ }^{+}$salt, thus regenerating the MOR-1-HA column.

\section{Conclusions}

Clearly, metal-organic resins (MORs) can be the next generation of resins, since their sorption capability is not only based on the functional-binding group (as occurs with the conventional organic resins) but also on their highly ordered porous structure enhancing the diffusion of ions and the sorption kinetics. Such materials, however, due to their very small particle size form fine suspensions in water, thus being not suitable for water treatment applications. We were able to overcome this limitation of MORs by engineering MORalginic acid (HA) composite form, in which the MOR particles are covered by a water-insoluble HA shell. Thus, the successful utilization of MOR-HA composite as stationary phase in ionexchange columns was achieved. The excellent performance of such ion exchange columns, as demonstrated by their high efficiency for removal of $\mathrm{Cr}(\mathrm{vI})$ under a variety of conditions, points towards real-world environmental remediation applications of MOR-based sorbents.

\section{Acknowledgements}

The powder X-ray diffraction unit of the Network of Research Supporting Laboratories at the University of Ioannina is acknowledged. The work performed at Northwestern University was supported by National Science Foundation grant DMR1410169.

\section{References}

1 E. A. Katayev, Y. A. Ustynyuk and J. L. Sessler, Coord. Chem. Rev., 2006, 250, 3004.

2 (a) M. Costa and C. B. Klein, Crit. Rev. Toxicol., 2006, 36, 155; (b) F. Brito, J. Ascanio, S. Mateo, C. Hernandez, L. Araujo, P. Gili, P. MartinZarza, S. Dominguez and A. Mederos, Polyhedron, 1997, 16, 3846.

3 (a) USA-EPA. Chromium in drinking water, http:// water.epa.gov/drink/info/chromium/; $\quad(b) \quad$ European Commission. Council Directive 98/83/EC on the quality of water intended for human consumption, http://eur-lex. europa.eu/legal-content/EN/TXT/?uri=CELEX:31998L0083; (c) C. S. Peng, H. Meng, S. X. Song, S. Lu and A. LopezValdivieso, Sep. Sci. Technol., 2004, 39, 1501.

4 (a) R. W. Liang, F. F. Jing, L. J. Shen, N. Qin and L. Wu, J. Hazard. Mater., 2015, 287, 364; (b) L. B. Hoch, E. J. Mack, B. W. Hydutsky, J. M. Hershman, I. M. Skluzacek and T. E. Mallouk, Environ. Sci. Technol., 2008, 42, 2600.

5 A. A. Zagorodni, Ion Exchange Materials, Properties and Applications, Elsevier, 2007.

6 M. J. McGuire, N. Blute, G. Qin, P. Kavounas, D. Froelich, and F. Leighton, Hexavalent Chromium Removal Using Anion
Exchange and Reduction with Coagulation and Filtration, AWWA Research Foundation, 2007.

7 S. Kaneko and M. Ogawa, Appl. Clay Sci., 2013, 75-76, 109. 8 (a) M. Eddaoudi, D. B. Moler, H. L. Li, B. L. Chen, T. M. Reineke, M. O'Keeffe and O. M. Yaghi, Acc. Chem. Res., 2001, 34, 319; (b) G. Ferey, Chem. Soc. Rev., 2008, 37, 191; (c) S. Horike, S. Shimomura and S. Kitagawa, Nat. Chem., 2009, 1, 695; (d) D. Bradshaw, J. B. Claridge, E. J. Cussen, T. J. Prior and M. J. Rosseinsky, Acc. Chem. Res., 2005, 38, 273; (e) O. K. Farha and J. T. Hupp, Acc. Chem. Res., 2010, 43, 1166; $(f)$ S. T. Zheng, T. Wu, J. A. Zhang, M. Chow, R. A. Nieto, P. Y. Feng and X. H. Bu, Angew. Chem., Int. Ed., 2010, 49, 5362.

9 (a) H. H. Fei, M. R. Bresler and S. R. J. Oliver, J. Am. Chem. Soc., 2011, 133, 11110; (b) H. H. Fei, C. S. Han, J. C. Robins and S. R. J. Oliver, Chem. Mater., 2013, 25, 647; (c) H. R. Fu, Z. X. Xu and J. Zhang, Chem. Mater., 2015, 27, 205; (d) X. X. Li, H. Y. Xu, F. Z. Kong and R. H. Wang, Angew. Chem., Int. Ed., 2013, 52, 13769; (e) P. F. Shi, B. Zhao, G. Xiong, Y. L. Hou and P. Cheng, Chem. Commun., 2012, 48, 8231; (f) Q. Zhang, J. Yu, J. Cai, L. Zhang, Y. Cui, Y. Yang, B. Chen and G. Qian, Chem. Commun., 2015, 51, 14732.

10 G. Tchobanoglous, F. L. Burton and H. D. Stensel, Wastewater engineering: treatment, disposal, and reuse, McGraw-Hill, 1991.

11 (a) J. H. Cavka, S. Jakobsen, U. Olsbye, N. Guillou, C. Lamberti, S. Bordiga and K. P. Lillerud, J. Am. Chem. Soc., 2008, 130, 13850; (b) M. J. Katz, Z. J. Brown, Y. J. Colon, P. W. Siu, K. A. Scheidt, R. Q. Snurr, J. T. Hupp and O. K. Farha, Chem. Commun., 2013, 49, 9449; (c) M. Kandiah, M. H. Nilsen, S. Usseglio, S. Jakobsen, U. Olsbye, M. Tilset, C. Larabi, E. A. Quadrelli, F. Bonino and K. P. Lillerud, Chem. Mater., 2010, 22, 6632; (d) A. J. Howarth, M. J. Katz, T. C. Wang, A. E. Platero-Prats, K. W. Chapman, J. T. Hupp and O. K. Farha, J. Am. Chem. Soc., 2015, 137, 7488; (e) K. K. Yee, N. Reimer, J. Liu, S. Y. Cheng, S. M. Yiu, J. Weber, N. Stock and Z. T. Xu, J. Am. Chem. Soc., 2013, 135, 7795; (f) C. B. He, K. D. Lu and W. B. Lin, J. Am. Chem. Soc., 2014, 136, 12253; (g) L. Zhu, D. Zhang, M. Xue, H. Li and S. Qiu, CrystEngComm, 2013, 15, 9356; (h) W. Morris, W. E. Briley, E. Auyeung, M. D. Cabezas and C. A. Mirkin, J. Am. Chem. Soc., 2014, 136, 7261.

12 (a) A. I. Spjelkavik, Aarti, S. Divekar, T. Didriksen and R. Blom, Chem.-Eur. J., 2014, 20, 8973; (b) Y. H. Li, F. Q. Liu, B. Xia, Q. J. Du, P. Zhang, D. C. Wang, Z. H. Wang and Y. Z. Xia, J. Hazard. Mater., 2010, 177, 876; (c) M. G. Kanatzidis, D. Sarma and M. J. Manos, Column material for the capture of heavy metal and precious metal ions, US Pat., 20150144568, 2015.

13 (a) M. Bosnic, J. Buljan, R. P. Daniels and S. Rajamani, Pollutants in tannery effluent, published online, 2003, http:// leatherpanel.org/sites/default/files/publications-attachments/ polutants.pdf; (b) F. Akbal and S. Camci, Desalination, 2011, 269, 214. 
14 (a) M. C. Biesinger, C. Brown, J. R. Mycroft, R. D. Davidson and N. S. McIntyre, Surf. Interface Anal., 2004, 36, 1550; (b) E. Desimoni, C. Malitesta, P. G. Zambonin and J. C. Riviere, Surf. Interface Anal., 1988, 13, 173.

15 (a) M. J. Manos, N. Ding and M. G. Kanatzidis, Proc. Natl. Acad. Sci. U. S. A., 2008, 105, 3696; (b) M. J. Manos and M. G. Kanatzidis, J. Am. Chem. Soc., 2009, 131, 6599; (c) M. J. Manos and M. G. Kanatzidis, Chem.-Eur. J., 2009, 15, 4779; (d) M. J. Manos and M. G. Kanatzidis, J. Am. Chem. Soc., 2012, 134, 16441; (e) M. J. Manos, V. G. Petkov and M. G. Kanatzidis, Adv. Funct. Mater., 2009, 19, 1087; $(f)$ J. L. Mertz, Z. H. Fard, C. D. Malliakas, M. J. Manos and M. G. Kanatzidis, Chem. Mater., 2013, 25, 2116.

16 A. Benhammou, A. Yaacoubi, L. Nibou and B. Tanouti, J. Colloid Interface Sci., 2005, 282, 320.

17 (a) M. Karabacak, M. Cinar, Z. Unal and M. Kurt, J. Mol. Struct., 2010, 982, 22; (b) D. Lin-Vien, N. Colthup, W. Fateley and J. Grasseli, The Handbook of Infrared and
Raman Characteristic Frequencies of Organic Molecules, Academic Press, 1991; (c) M. Tanaka and S. Ogasawar, J. Catal., 1972, 25, 111.

18 Two crystal structures of tetrahedral $\left[\mathrm{L}\left(\mathrm{Cr}^{\mathrm{VI}} \mathrm{O}_{3}\right]\right.$ complexes are reported in the following references: (a) M. R. Sundberg, R. A. M. Uggla, R. Sillanpaa, K. K. Zborowski, A. Sanchez-Gonzalez, J. K. T. Matikainen, S. A. A. Kaltia and T. A. Hase, Cent. Eur. J. Chem., 2010, 8, 486; (b) W. Mazurek, G. D. Fallon, P. J. Nichols and B. O. West, Polyhedron, 1990, 9, 777.

19 F. Brito, J. Ascanio, S. Mateo, C. Hernandez, L. Araujo, P. Gili, P. MartinZarza, S. Dominguez and A. Mederos, Polyhedron, 1997, 16, 3835.

20 (a) H. H. Sisler, J. D. Bush and O. E. Acoountius, J. Am. Chem. Soc., 1948, 70, 3827; (b) G. I. Poos, G. E. Arth, R. E. Beyler and L. H. Sarett, J. Am. Chem. Soc., 1953, 75, 422; (c) G. Tojo and M. Fernandez, Oxidation of Alcohols to Aldehydes and Ketones, Springer, Berlin, 2006, pp. 1-97. 